\title{
Pore Size Distribution Influence on Suction Properties of Calcareous Stones in Cultural Heritage: Experimental Data and Model Predictions
}

\author{
Giorgio Pia, Ludovica Casnedi, and Ulrico Sanna \\ Dipartimento di Ingegneria Meccanica, Chimica e dei Materiali, Università degli Studi di Cagliari, Piazza d’Armi, \\ 09123 Cagliari, Italy
}

Correspondence should be addressed to Giorgio Pia; giorgio.pia@dimcm.unica.it

Received 3 January 2016; Accepted 23 March 2016

Academic Editor: Michael Aizenshtein

Copyright (C) 2016 Giorgio Pia et al. This is an open access article distributed under the Creative Commons Attribution License, which permits unrestricted use, distribution, and reproduction in any medium, provided the original work is properly cited.

\begin{abstract}
Water sorptivity symbolises an important property associated with the preservation of porous construction materials. The water movement into the microstructure is responsible for deterioration of different types of materials and consequently for the indoor comfort worsening. In this context, experimental sorptivity tests are incompatible, because they require large quantities of materials in order to statistically validate the results. Owing to these reasons, the development of analytical procedure for indirect sorptivity valuation from MIP data would be highly beneficial. In this work, an Intermingled Fractal Units' model has been proposed to evaluate sorptivity coefficient of calcareous stones, mostly used in historical buildings of Cagliari, Sardinia. The results are compared with experimental data as well as with other two models found in the literature. IFU model better fits experimental data than the other two models, and it represents an important tool for estimating service life of porous building materials.
\end{abstract}

\section{Introduction}

Cultural heritage preservation is an important issue in Material Science field. The main damage causes of historical bricks, earth masonry, and stones are related to the circulation of water in their microstructures [1-3]. The water presence may be owing to several origins: infiltrations from different parts of buildings such as walls, roof, water, and sanitary systems; atmospheric conditions and environmental events such as high air relative humidity, rain, snow, flooding, hygroscopic salts, and capillary rise. Certainly, the latter represents the most common phenomenon, by which the water is conveyed within the microstructure of porous building materials $[4,5]$.

Indeed, capillary rise is involved in several damage processes, such as salt-crystallisation cycles [6], freezing-thawing cycles [7], dissolution of soluble fractions [8], biological decay [1], chemical attack in polluted environment [1], swelling of clays [9], and reduction of mechanical properties [10]. Consequent on these deteriorations of microstructures, the open porosity and the resulting capability of absorbing water are increased and material's durability is further compromised.

The presence of damp walls as well as reduced durability of materials gives rises to uncomfortable indoor thermalhygrometric conditions owing to the high values of air relative humidity and the lower thermal insulation performance [1].

In order to diminish the movement of water into the material's microstructure, several surface treatments for consolidation and protection are usually applied. The results consist of the reduction of sorption properties by partly occluding pores or by altering material's hydrophilic behaviour [11, 12].

Although consolidating and/or protective treatments reduce the kinematic of weathering, they should not arrest completely liquid water and water vapour flux between the material and the internal or external environment [13]. In fact, the possible presence of water or water vapours trapped behind a treated surface could represent a material damage cause (capillary overpressure, salt-crystallisation cycles, freezing-thawing cycles, etc.) $[1,14]$. 
In this context, water sorptivity $(S)$, defined as water volume absorbed per unit surface area per square root time, results in a key parameter to evaluate the service life of porous building materials as well as of the entire building [1]. Water sorptivity test on stone is performed on regular samples (prisms or cylinders) in accordance with the Italian Guideline NORMAL 20/85 [15]. This test is very simple to perform in the laboratory, but it requires large quantities of materials in order to statistically validate the results. This fact is incompatible when the sorptivity is measured on materials from cultural heritage, which are subjected to specific and strict regulations for their safety. In these cases, only small and irregular samples may be withdrawn from historical buildings, but they do not have suitable dimensions to measure sorptivity coefficient. However, these small samples can be used to perform Mercury Intrusion Porosimetry (MIP) tests. The possibility to develop analytical procedure for indirect sorptivity valuation from MIP data would be highly beneficial. In this regard, in order to correlate sorptivity with properties of both liquid (density, surface tension, contact angle with material, and viscosity) and material (open porosity, average pore radius, and tortuosity), diverse models have been proposed $[12,16]$. However, these modelling procedures are validated only for specific category of materials. Several applications have led to values generally different from the experimental data even by an order of magnitude [16].

Such difficulties in reproducing experimental data are probably owing to the extreme simplicity, with which the microstructure is described. These formulas take into account total open porosity, average pore size, and tortuosity by ignoring entire pore size range and pore size distribution, which generally have been studied much less [16, 17]. These characteristics influence the sorption phenomenon; for example, thinner pores absorb water slower than larger pores, but height of water rise is higher [12]. In this way, considering the only average pore size results in significant computational errors in sorptivity predictions, and it can only provide a rough description of complex systems such as real natural stones, which can have pores with different and varying size.

In order to elaborate a model procedure capable of predicting sorptivity values, the description of microstructure features must be taken into account. For this reason, fractal geometry results are of great interest. It has been formalised and developed during 1970s by Mandelbrot [18] that fractals are characterised by noninteger dimension $\left(D_{f}\right)$, intricate and fine structure, geometric construction based on iteration procedure, and self-similarity, which consists of structure configurations that are repeated at different scales [19].

Fractal characteristics have been recognised in a large number of forms in organic as well as inorganic systems of nature and even, more importantly, in several aspects of the microstructure of the materials $[18,19]$.

This fact has been found relevant to describe and predict different aspects of their macroscopic behaviour. For example, in cement and concrete materials, fractal geometry has been used to estimate the pore surface complexity as a function of the kneading water. The results have indicated that kneading water does not change the pore surface, but it is only responsible for the swelling of the structure [20]. It has also been demonstrated that hydrated cement pastes have highly irregular surfaces with fractal characteristics, which are responsible for the anomalies observed in vapour sorption experiments to determine surface area [21].

Moreover, a general model developed from fractal modelling of a porous medium was used in order to match experimental capillary pressure for the geyser rock [22]. It has been demonstrated that the heterogeneity of this rocktype can be evaluated quantitatively using the calculated fractal dimension [22]. An important application of fractal geometry to describe physical phenomena of porous materials has been conducted by Cai and his work group [2325]. They described spontaneous imbibition of wetting liquid into porous media with an analytical fractal model, which take into account tortuosity effect [26, 27], finding a good agreement with experimental data. Recently, an Intermingled Fractal Units (IFU) model has been proposed to correlate structure and properties (thermal performance, mechanical behaviour, and water circulation into the microstructure) of several categories of materials: cement and concrete [28], ceramics [29, 30], earth based materials [31, 32], and stones $[33,34]$.

IFU model is characterised by a close correlation with porous microstructure, and it is also capable of reproducing nonfractal pore size distributions. This represents an important aspect as all microstructures cannot be considered being fractals. After microstructure reproduction, being fractals geometries analytically known, the model can lead back to mathematical expressions for calculating the physical properties.

In this paper, an IFU model has been proposed in order to predict sorptivity coefficient of porous materials used in cultural heritage. This approach facilitates evaluating water absorption without the necessity to have large quantities of materials. The experimental tests are carried out on calcareous stone, from quarries, commonly used in historical building of Cagliari (Sardinian). IFU calculated sorptivity coefficient has been compared with experimental data as well as with the results obtained by two other models. IFU model predictions are better in agreement with experimental data than the other models' calculations reported in Scherer and Wheeler [12] and Raimondo et al. [16].

\section{Materials and Methods}

The experimental investigation was carried out on a limestone from the quarries of Cagliari, popularly named Cantone stone. This stone, owing to easy availability and workability, has been widely used in this city for most of the popular and noble historical buildings. However, it is predominantly susceptible to atmospheric agents as well as to the effects of degradation caused by water. 

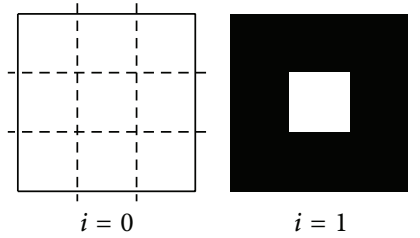

$i=1$

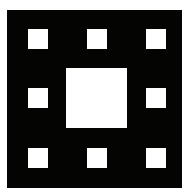

$i=2$

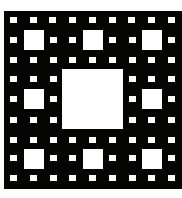

$i=3$

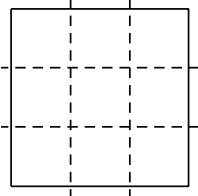

$i=0$

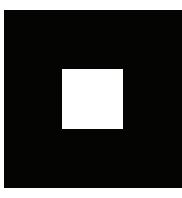

$i=1$

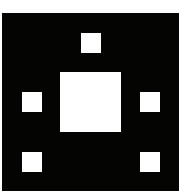

$i=2$

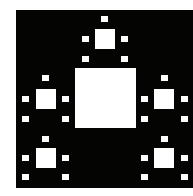

$i=3$

(a)

(b)

FIGURE 1: Sierpinski carpet construction: (a) all the eight subsquares are involved in self-similarity process; (b) only five subsquares reproduce the configuration of the first iteration, and the other three remain solid forever.

For this study, three blocks of limestone (A, B, and C) of $40 \times 40 \times 10 \mathrm{~cm}$ size were investigated. They have been withdrawn from different parts of the quarry for the evaluation of the heterogeneity of this stone.

Therefore, the tests were conducted on samples visibly free from damage and macroscopic fossils' remains. Subsequently, the blocks were cut into cubes of $5 \mathrm{~cm}$ using a rotating diamond blade saw. Each block has been divided into ten samples (A1-A10, B1-B10, and C1-C10).

The porosity, cumulative pore volume curves, and relative pore size distribution are evaluated with the help of Mercury Intrusion Porosimetry Technique. The porosimeter is the Micrometrics AutoPore IV, which automatically records pressure, pore radius, intrusion volume, pore surface area, and bulk density.

The capillary absorption test was performed in accordance with UNI EN 15801 [35]. Before the test, the samples were dried in the ventilated oven at a temperature of $60^{\circ} \mathrm{C}$ for 24 hours until constant weight. Subsequently, the samples were exposed to the distilled water on one face by placing them on a pan over the sheets of filter paper, which is kept constantly wet. The samples, at regular time intervals, have been extracted from the pan, towel-dried, and weighed using a balance, and then the amount of water absorbed was calculated with respect to the cross section area of the specimens. The amount of water absorbed per unit area $Q_{i}$ $\left(\mathrm{mg} / \mathrm{cm}^{2}\right)$ at time $t_{i}(\mathrm{~s})$ is calculated using $Q_{i}=\left[\left(m_{i}-\right.\right.$ $\left.\left.m_{0}\right) / A_{s}\right]$, where $m_{i}(\mathrm{mg})$ is the mass of the specimen at time $t_{i}, m_{o}(\mathrm{mg})$ is the mass of the dry specimen, and $A_{s}\left(\mathrm{~cm}^{2}\right)$ is the area of the sample in contact with the water.

The sorptivity $\left(S_{\text {exp }}\right)$ is the slope of the linear section of the curve obtained by plotting the mass change per area $\left(Q_{i}\right)$ versus the square root of time $\left(t_{i}^{1 / 2}\right)$ and was determined by linear regression using at least 5 successive aligned points.

\section{Intermingled Fractal Units Model}

The Intermingled Fractal Units model consists of different base units and filled surface, which represent the porous and the nonporous parts of the model, respectively. Obviously, base units are fractal geometric figures based on Sierpinski carpet outline. The most popular design of Sierpinski carpet is achieved by commencing from a square with sides, which are divided according to a factor $(F)$ of 3 , resulting in a figure consisting of 9 subsquares, out of which one is removed.
The remaining 8 subsquares $(s)$ are involved in a new iteration process, which replicates the same configuration. In this way, the sides of the 8 subsquares are divided by the same length scale factor $(F)$ of 3 , generating a further 9 subsquares, from which 1 is again removed. The number of iterations (i) may continue ad infinitum, but reproducing an experimental pore size distribution depends on the pore size range.

The analytical expression to calculate fractal dimension $\left(D_{f}\right)$ of this Sierpinski carpet is

$$
D_{f}=\frac{\log (s)}{\log (F)} .
$$

The number of subsquares removed as well as the number of iterating and noniterating (solid forever) subsquares generates new type of Sierpinski carpet with different $D_{f}$ and consequently with diverse pore volume fraction $(\varepsilon)$, pore size distribution, pore surface, and so forth. Figure 1(a) shows a Sierpinski carpet with a single pore at first iteration and the repetition of this configuration at every successive iteration. Figure 1(b) exhibits Sierpinski carpet with a single pore at first iteration but, from the second iteration onwards, the subsquares present 5 iterating squares as well as 3 solid forever squares.

A hypothetical mercury intrusion on the extruded Sierpinski carpet gives rise to a pore size distribution, in which the maximum adsorption corresponds to maximum pore ray. Porous building materials can have different types of pore size distribution, out of which maximum coincides with a generic pore radius or there may be more peaks corresponding to several pore sizes of the radius range [17]. In both cases, these pore size distributions are not typically fractal.

However, recent works have revealed that different fractal units, intermingled together, can reproduce even real nonfractal structures. This modelling procedure is called Intermingled Fractal Units (IFU) model, and it is capable of simulating porous experimental microstructures: pore volume fraction $\left(\varepsilon_{\exp }\right)$ and pore size distribution $[26,35]$ (Figures 2(a), 2(b), and 2(c)).

The proposed IFU model consists of two types of base units $\mathrm{A}$ and B. For each $\mathrm{A}$ base unit, there are intermingled $n_{\mathrm{B}}$ of $\mathrm{B}$ base units. The $n_{\mathrm{B}}$ value is calculated by the following formula:

$$
n_{\mathrm{B}}=\frac{\left(A_{\mathrm{A} p}-\varepsilon \cdot A_{\mathrm{A}}\right)}{\left(\varepsilon_{\exp } \cdot A_{\mathrm{B}}-A_{\mathrm{B} p}\right)},
$$




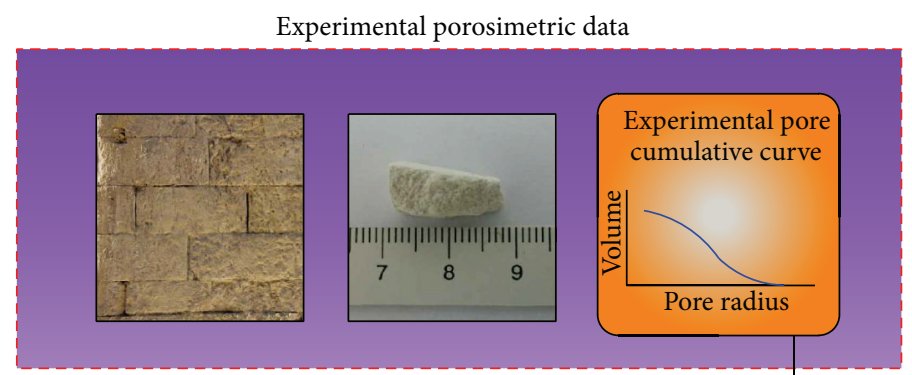

(a)

Intermingled fractal units model construction

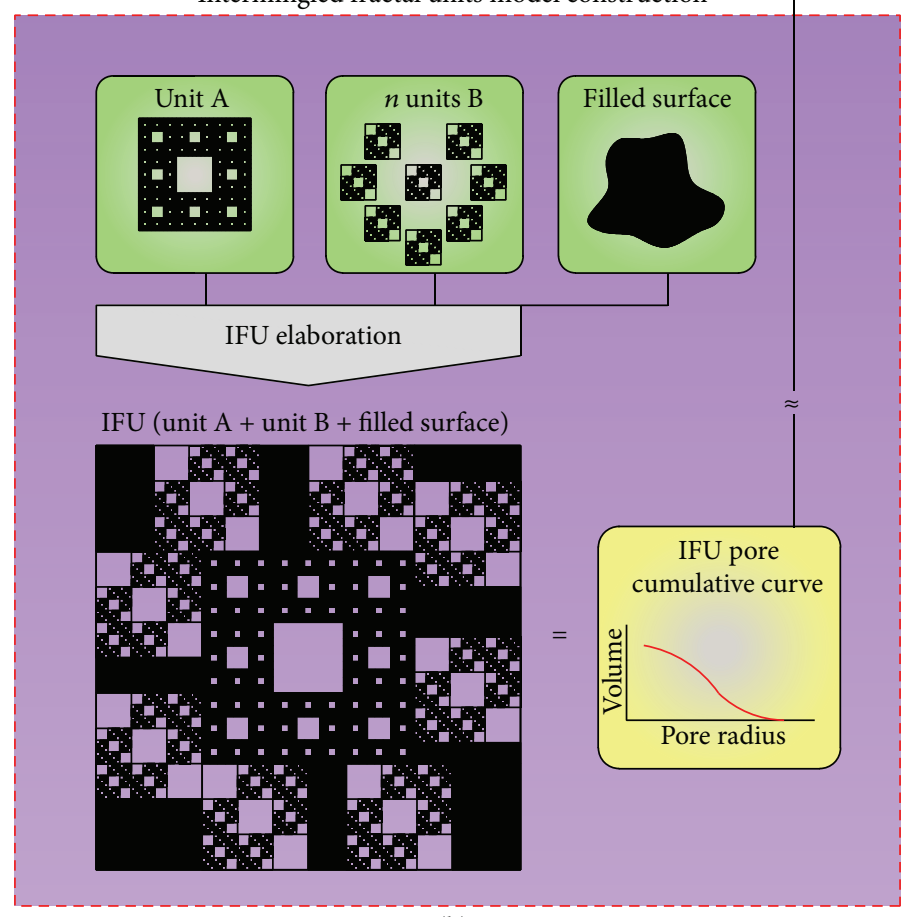

(b)

Comparison between experimental and calculated data

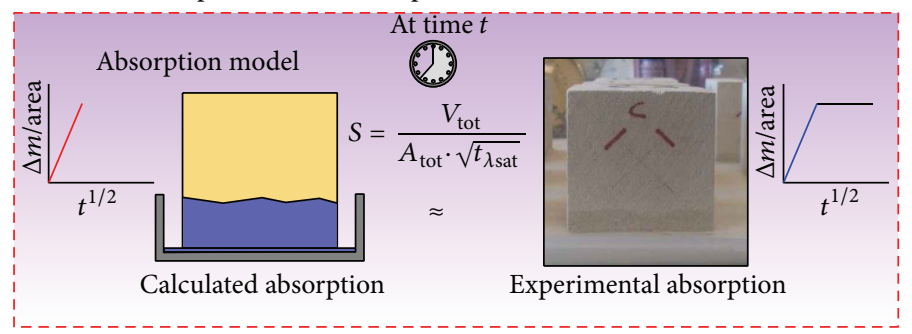

(c)

FIGURE 2: IFU procedure to reproduce porous microstructures and to calculate their sorptivity. (a) Starting point is represented by MIP tests and consequent mercury intrusion pore cumulative curve. (b) In order to reproduce this microstructure, two elementary units, based on Sierpinski carpet, and a portion of filled surface are used. After having compared experimental and IFU curves, IFU model is broken down again in the base units, and the analytical procedure is applied. (c) The calculated IFU sorptivity $\left(S_{\mathrm{IFU}}\right)$ can be compared with the data acquired experimentally $\left(S_{\text {exp }}\right)$.

where $A_{\mathrm{A}}, A_{\mathrm{B}}, A_{\mathrm{A} p}$, and $A_{\mathrm{B} p}$ are the total areas and the total pore areas of units $A$ and $B$ (Figure $2(b)$ ) and $\varepsilon_{\text {exp }}$ is the experimental pore volume fraction.

The versatility of the model is ensured by the fact that the base units have different maximum pore sizes, whereas they could have different number of removed squares as well as fractal dimensions, iterations, pore volume fraction, and so forth.

In order to control the value of the pore volume fraction, it could be advantageous to integrate sufficient parts 
of IFU filled surface or consider some subsquares solid forever.

This model's features guarantee a particular aptitude to reproduce the most different pore size distributions experimentally verifiable.

Water capillary absorption speed depends upon the size of pores. For example, large pores absorb water more quickly than thinner pores. In this context, sorptivity values, defined by the slope of the rectilinear section of the curve between water absorption per unit area and square root of time, are strongly influenced by pore size range and pore size distribution of materials.

Owing to these reasons, IFU model, capable of reproducing porous microstructure, can be a valuable tool in order to calculate sorption properties. Indeed, in order to calculate sorptivity, the flow of fluid, which passes through every base unit of IFU, must be considered. For a Sierpinski carpet, the number of pores is defined by

$$
N_{\text {pores }(i=n)}=F^{i \cdot D_{f}}\left(F^{2-D_{f}}-1\right) .
$$

In this case, $i=2, F=3$, and $D_{f}=1.89$. Thus, $N_{\text {pores }(i=n)}=$ $3^{2 \cdot 1.89}\left(3^{2-1.89}-1\right)=8$, as shown in Figure 1. Indeed, the second iteration generates 8 new pores.

According to Hagen-Poiseuille equation [36], the fluid flow for a single capillary with section calculated as that of the circumference inscribed in the square subtracted is given by

$$
q(\lambda)=\frac{\pi}{128} \frac{\Delta p}{L_{t}(\lambda)} \frac{\lambda^{4}}{\mu}
$$

where $\Delta p$ is the pressure loss, $L_{t}$ is tortuous capillary length, $\lambda$ is the pore diameter, and $\mu$ is dynamic viscosity.

In this model, every base unit is extruded. So the pores have rectilinear path. Consequently, the fractal dimension of tortuosity is $D_{t}=1$ and the height of the sample is equal to the pore length [26]:

$$
L_{t}(\lambda)=L_{0}{ }^{D_{t}} \lambda^{1-D_{t}}=L_{0}=h_{\text {sample }} .
$$

Moreover, a generic pore diameter can be expressed as the function of the maximum pore diameter of Sierpinski carpet:

$$
\lambda=\frac{\lambda_{\max }}{F^{(i-1)}} .
$$

Considering (6), Hagen-Poiseuille equation can be rewritten as

$$
q_{\text {pore }}(\lambda)=\frac{\pi}{128} \frac{\Delta p}{L_{0}} \frac{1}{\mu} \frac{\lambda_{\max }^{4}}{F^{4(i-1)}} .
$$

In order to calculate the total flow $\left(Q_{\text {class }}\right)$ for a generic pore class, the number of pores must be taken into account:

$$
\mathrm{Q}_{\text {class }}=q_{\text {pore }} \cdot N \text {. }
$$

Simple algebra shows that

$$
Q_{\text {class }}=\left(\frac{\pi}{128} \frac{\Delta p}{L_{0}} \frac{1}{\mu} \frac{\left(\lambda_{\max }\right)^{4}}{F^{4(i-1)}}\right) \cdot\left(F^{i \cdot D_{f}}\left(F^{2-D_{f}}-1\right)\right) .
$$

The average speed of water rising $A_{p}$ as total porous surface will be given by

$$
v=\frac{Q}{A_{p}},
$$

where $Q$ is IFU total flow and $A_{p}$ is IFU total pore surface.

The time $\left(t_{\text {sat }}\right)$ that the fluid takes to saturate different single pore is defined as

$$
\begin{gathered}
t_{\text {sat }}=h_{\text {sample }} \cdot\left[\frac{1}{A_{p}}\left(\frac{\pi}{128} \frac{\Delta p}{L_{0}} \frac{1}{\mu} \frac{\left(\lambda_{\max }\right)^{4}}{F^{4(i-1)}}\right)\right. \\
\left.\cdot\left(F^{i \cdot D_{f}}\left(F^{2-D_{f}}-1\right)\right)\right]^{-1} .
\end{gathered}
$$

Considering $t_{\lambda \text { sat }}$ as the water saturation time of the most significant category of pores, it is possible to estimate different heights reached by the water on the thinner pores (eventually, for the pores larger than the representative pore diameter at $t_{\text {sat }}$, they are considered saturated).

Consequently, the volume of fluid absorbed could be calculated by

$$
V_{\text {tot }}=\sum_{1}^{n} A_{p} \cdot h_{\text {class }} \text {. }
$$

Considering the total absorbent surface $\left(A_{\text {tot }}\right)$, sorptivity is equal to

$$
S=\frac{V_{\text {tot }}}{A_{\text {tot }} \cdot \sqrt{t_{\lambda \mathrm{sat}}}} .
$$

IFU calculated sorptivity can be compared with experimental and/or other model sorptivity data $[12,16]$.

\section{Results}

Capillary absorption tests exhibit, as expected, dependence on pore volume fraction, even if it is possible to note that pore size distribution influences the sorptivity value. Although the limestone can have strongly heterogeneous porous microstructures [37], the differences between the blocks of Cantone stone (A, B, and C) justify the different values of the absorption coefficients.

Table 1 shows experimental values obtained by Mercury Intrusion Porosimetry Technique: total pore volume, pore volume for different pore size ranges, average pore radius, specific surface area, and bulk density. The average porosity value is $32.48 \%$ for $\mathrm{A}, 34.40 \%$ for $\mathrm{B}$, and $37.82 \%$ for $\mathrm{C}$. In order to underline the main differences between three blocks (A, B, and $C$ ), three pore range classes have been proposed. Indeed, in Table 1 , it is possible to note the relative porosity percentage for the specific pore range. The first $P 1$ is $60 \div 3.61 \mu \mathrm{m}$, the second $P 2$ is $3.60 \div 0.17 \mu \mathrm{m}$, and the third is $0.16 \div 0.02 \mu \mathrm{m}$.

Generally, the limestone's block $\mathrm{C}$ has a greater quantity of pore volume in $P 1, P 2$, and $P 3$ range than blocks $A$ and $\mathrm{B}$.

Consequent on the difference in their pore size distributions, the kinetics of water capillary absorption is perturbed 
TABLE 1: Microstructural characteristics of the samples. Total pore volume $(P)$, porosity in the first range $(P 1)$, porosity in the second range $(P 2)$, porosity in the third range $(P 3)$, average pore radius (APR), specific surface area (SSA), and bulk density $\left(\delta_{g}\right)$.

\begin{tabular}{|c|c|c|c|c|c|c|c|}
\hline Sample & $P(\%)$ & $\begin{array}{c}P 1(\%) \\
60 \div 3.61 \mu \mathrm{m}\end{array}$ & $\begin{array}{c}P 2(\%) \\
3.60 \div 0.17 \mu \mathrm{m}\end{array}$ & $\begin{array}{c}P 3(\%) \\
0.16 \div 0.02 \mu \mathrm{m}\end{array}$ & $\begin{array}{l}\text { APR } \\
(\mu \mathrm{m})\end{array}$ & $\begin{array}{c}\text { SSA } \\
\left(\mathrm{m}^{2} / \mathrm{g}\right)\end{array}$ & $\begin{array}{c}\delta_{g} \\
\left(\mathrm{~g} / \mathrm{cm}^{3}\right)\end{array}$ \\
\hline $\mathrm{A} 1$ & 0.31 & 3.08 & 25.92 & 1.51 & 1.18 & 0.48 & 1.70 \\
\hline $\mathrm{A} 2$ & 0.31 & 3.12 & 26.25 & 1.53 & 1.21 & 0.49 & 1.66 \\
\hline A3 & 0.31 & 3.13 & 26.33 & 1.53 & 1.2 & 0.49 & 1.68 \\
\hline A4 & 0.31 & 3.13 & 26.36 & 1.53 & 1.07 & 0.49 & 1.67 \\
\hline A5 & 0.32 & 3.21 & 26.98 & 1.57 & 1.11 & 0.49 & 1.56 \\
\hline A6 & 0.32 & 3.28 & 27.59 & 1.60 & 1.32 & 0.51 & 1.59 \\
\hline A7 & 0.33 & 3.30 & 27.80 & 1.62 & 1.23 & 0.51 & 1.64 \\
\hline A8 & 0.34 & 3.41 & 28.64 & 1.66 & 1.32 & 0.53 & 1.56 \\
\hline A9 & 0.35 & 3.49 & 29.32 & 1.70 & 1.22 & 0.54 & 1.55 \\
\hline $\mathrm{A} 10$ & 0.35 & 3.52 & 29.64 & 1.72 & 1.15 & 0.54 & 1.51 \\
\hline B1 & 0.33 & 3.82 & 27.38 & 1.30 & 1.32 & 0.21 & 1.53 \\
\hline B2 & 0.33 & 3.87 & 27.70 & 1.32 & 1.45 & 0.22 & 1.52 \\
\hline B3 & 0.33 & 3.88 & 27.78 & 1.32 & 1.49 & 0.28 & 1.51 \\
\hline B4 & 0.33 & 3.88 & 27.79 & 1.32 & 1.49 & 0.28 & 1.51 \\
\hline B5 & 0.33 & 3.88 & 27.8 & 1.32 & 1.49 & 0.28 & 1.51 \\
\hline B6 & 0.36 & 4.19 & 30.04 & 1.43 & 1.45 & 0.40 & 1.50 \\
\hline B7 & 0.36 & 4.20 & 30.08 & 1.43 & 1.50 & 0.45 & 1.48 \\
\hline B8 & 0.36 & 4.21 & 30.16 & 1.43 & 1.60 & 0.50 & 1.48 \\
\hline B9 & 0.36 & 4.21 & 30.16 & 1.43 & 1.87 & 0.50 & 1.53 \\
\hline B10 & 0.36 & 4.21 & 30.16 & 1.43 & 1.87 & 0.50 & 1.53 \\
\hline $\mathrm{C} 1$ & 35.68 & 5.54 & 28.77 & 1.59 & 1.60 & 0.37 & 1.72 \\
\hline $\mathrm{C} 2$ & 35.77 & 5.55 & 28.85 & 1.59 & 1.60 & 0.38 & 1.70 \\
\hline C3 & 36 & 5.59 & 29.03 & 1.60 & 1.54 & 0.39 & 1.65 \\
\hline $\mathrm{C} 4$ & 36.02 & 5.59 & 29.05 & 1.60 & 1.56 & 0.39 & 1.68 \\
\hline C5 & 38.26 & 5.94 & 30.85 & 1.70 & 1.50 & 0.63 & 1.6 \\
\hline C6 & 38.40 & 5.96 & 30.97 & 1.71 & 1.10 & 0.82 & 1.38 \\
\hline C7 & 38.65 & 6.00 & 31.17 & 1.72 & 1.45 & 0.69 & 1.50 \\
\hline $\mathrm{C} 8$ & 38.7 & 6.00 & 31.21 & 1.72 & 1.11 & 0.74 & 1.01 \\
\hline C9 & 39.78 & 6.17 & 32.08 & 1.77 & 1.10 & 0.78 & 1.45 \\
\hline $\mathrm{C} 10$ & 40.89 & 6.34 & 32.98 & 1.82 & 1.05 & 0.82 & 1.38 \\
\hline
\end{tabular}

and the sorptivity coefficient becomes different. Figures 3(a), $3(\mathrm{~b})$, and $3(\mathrm{c})$ show the maximum and minimum water absorption of $\mathrm{A}, \mathrm{B}$, and $\mathrm{C}$ systems, respectively. The relevant water absorption occurs in the first 40 minutes. After this time, samples continue to absorb but with a lower velocity, until they reach the saturation.

According to the distribution of porosity along the pore size range, systems $\mathrm{A}, \mathrm{B}$, and $\mathrm{C}$ exhibit average sorptivity coefficients of $24.49,26.52$, and $28.04 \mathrm{mg} \mathrm{cm}^{-2} \mathrm{~s}^{-1 / 2}$, respectively.

In order to predict sorptivity value, an IFU model has been applied. Table 2 shows the input data (it reports the fractal dimension $\left(D_{f}\right)$, the maximum $\left(R_{\max }\right)$ and minimum $\left(R_{\min }\right)$ ray, the number of iterations, the number of solid forever squares for each base unit (Sierpinski carpet), and the filled surface used to build the IFU) in order to reproduce MIP pore cumulative curve. The results of this modelling for systems A3, B5, and C2 can be observed in Figure 4. The comparison between experimental and IFU model pore cumulative curves exhibits a good agreement. The observed errors are comparable with experimental ones. For this reason, after having simulated porous microstructure, the analytical procedure has been launched. IFU model findings are reported in Table 3, where it is possible to compare them with experimental data as well as the other two models reported in $[12,16]$ predictions. IFU model data is very close to experimental ones. While a greater difference has been shown by the calculation obtained by applying the latter two procedures, these differences are probably due to 

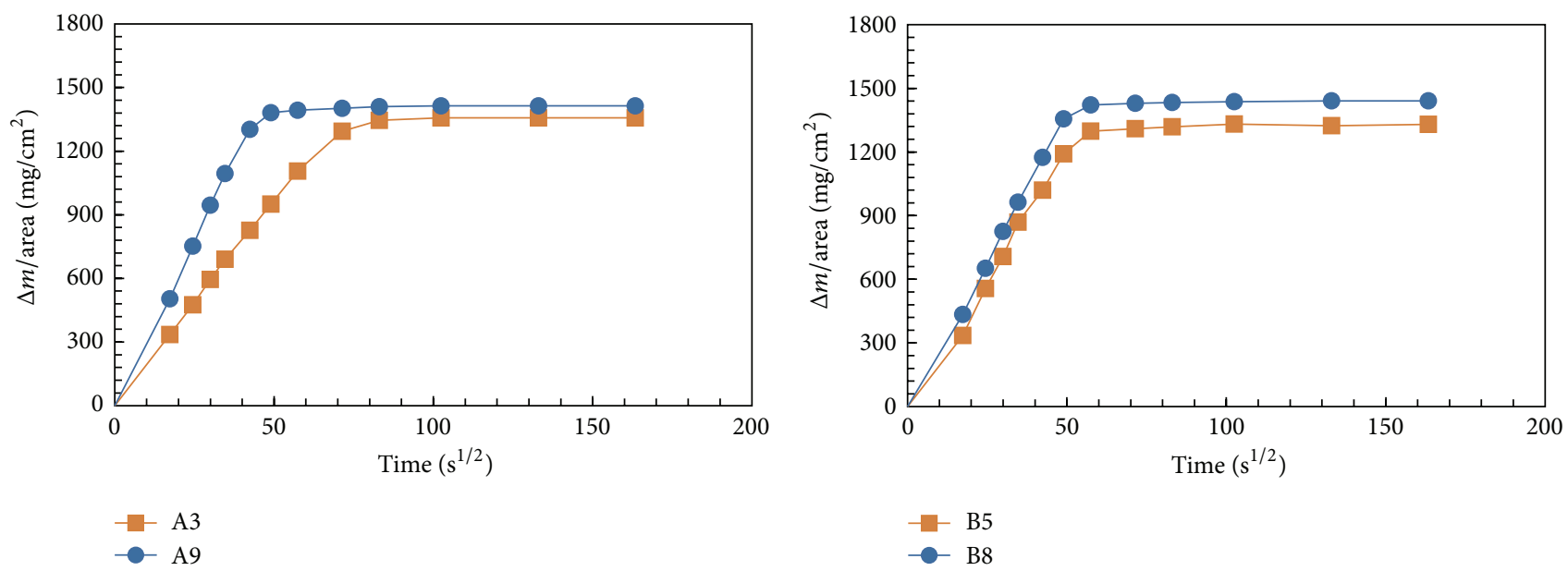

(a)

(b)

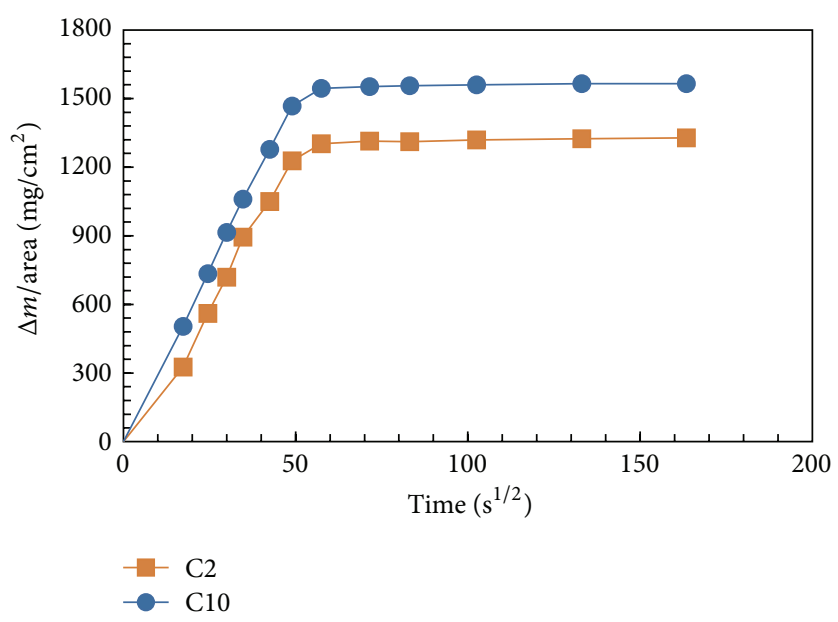

(c)

FIgURe 3: Maximum and minimum sorptivity for systems A, B, and C.

TABLE 2: IFU model input data for reproducing pore size distribution of samples A3, B5, and C2.

\begin{tabular}{lccc}
\hline & $\mathrm{A} 3$ & $\mathrm{~B} 5$ & $\mathrm{C} 2$ \\
\hline Unit A & & & \\
$D_{f}$ & 1.89 & 1.89 & 1.89 \\
$n$ & 1 & 1 & 1 \\
$R_{\max }(\mu \mathrm{m})$ & 44.81 & 44.73 & 44.77 \\
Iteration & 7 & 7 & 7 \\
$R_{\min }(\mu \mathrm{m})$ & 0.02 & 0.02 & 0.02 \\
Solid forever & 6 & 5 & 5 \\
Unit B & & & \\
$D_{f}$ & 1.77 & 1.77 & 1.77 \\
$n$ & 2549 & 2792 & 2792 \\
$R_{\max }(\mu \mathrm{m})$ & 1.66 & 1.65 & 1.65 \\
Iteration & 4 & 4 & 4 \\
$R_{\min }(\mu \mathrm{m})$ & 0.02 & 0.02 & 0.02 \\
Solid forever & 2 & 2 & 2 \\
\hline Filled surface $\left(\mu \mathrm{m}^{2}\right)$ & $9.28 \cdot 10^{4}$ & $8.32 \cdot 10^{4}$ & $5.09 \cdot 10^{4}$ \\
$\varepsilon_{\text {exp }} / \varepsilon_{\text {calc }}$ & $0.31 / 0.31$ & $0.33 / 0.33$ & $0.36 / 0.36$ \\
\hline
\end{tabular}

the fact that $S_{[12]}$ and $S_{[16]}$ are calculated only taking into consideration the mean pore radius but not the entire pore size distribution. Although, for some material, the mean pore may be representative, in this case, it is clearly not sufficient to describe pore microstructure of calcareous stones.

On the other hand, IFU modelling reliability in sorptivity calculation is owing to the capability of considering the entire pore size distribution, without neglecting any possible differences among volumes corresponding to different radii, which cannot be taken into account using only the average pore size.

Overall, IFU modelling has proved to be an important procedure for better understanding of the correlation between microstructures and properties of calcareous stones. It allows verifying the experimental findings that, in cultural heritage fields, are often difficult to obtain. For these reasons, IFU model has full potentiality to become a work instrument for estimating durability state and service life of porous building materials. 
TABLE 3: Sorptivity coefficient of calcareous stone. $S_{\text {exp }}$, experimental sorptivity; $S_{\text {IFU }}$, IFU sorptivity; $S_{[12]}$, sorptivity calculated according to the formula reported in Scherer and Wheeler [12]; $S_{[16]}$, value calculated according to the formula reported in Raimondo et al. [16] (values are accompanied by the relative error in the brackets).

\begin{tabular}{|c|c|c|c|c|}
\hline Sample & $\begin{array}{c}S_{\exp } \\
\left(\mathrm{mg} \mathrm{cm}^{-2} \mathrm{~s}^{-1 / 2}\right)\end{array}$ & $\begin{array}{c}S_{\mathrm{IFU}} \\
\left(\mathrm{mg} \mathrm{cm}^{-2} \mathrm{~s}^{-1 / 2}\right)\end{array}$ & $\begin{array}{c}S_{[12]} \\
\left(\mathrm{mg} \mathrm{cm}^{-2} \mathrm{~s}^{-1 / 2}\right)\end{array}$ & $\begin{array}{c}S_{[16]} \\
\left(\mathrm{mg} \mathrm{cm}^{-2} \mathrm{~s}^{-1 / 2}\right)\end{array}$ \\
\hline $\mathrm{A} 1$ & $26.62( \pm 0.05)$ & $22.85( \pm 0.04)$ & $70.36( \pm 0.06)$ & $127.89( \pm 0.05)$ \\
\hline A2 & $27.59( \pm 0.05)$ & $23.14( \pm 0.04)$ & $72.61( \pm 0.06)$ & $129.94( \pm 0.05)$ \\
\hline $\mathrm{A} 3$ & $19.52( \pm 0.04)$ & $23.22( \pm 0.03)$ & $72.66( \pm 0.04)$ & $129.76( \pm 0.04)$ \\
\hline A4 & $23.40( \pm 0.04)$ & $23.24( \pm 0.04)$ & $68.71( \pm 0.05)$ & $138.51( \pm 0.04)$ \\
\hline A5 & $25.80( \pm 0.05)$ & $23.31( \pm 0.04)$ & $72.46( \pm 0.06)$ & $152.48( \pm 0.05)$ \\
\hline A6 & $25.89( \pm 0.05)$ & $25.22( \pm 0.04)$ & $81.71( \pm 0.06)$ & $137.83( \pm 0.05)$ \\
\hline A7 & $21.74( \pm 0.04)$ & $25.22( \pm 0.03)$ & $79.79( \pm 0.05)$ & $140.57( \pm 0.04)$ \\
\hline A8 & $28.10( \pm 0.05)$ & $25.22( \pm 0.04)$ & $84.46( \pm 0.06)$ & $145.75( \pm 0.05)$ \\
\hline A9 & $29.46( \pm 0.06)$ & $21.37( \pm 0.04)$ & $86.08( \pm 0.07)$ & $156.92( \pm 0.06)$ \\
\hline $\mathrm{A} 10$ & $26.30( \pm 0.05)$ & $19.65( \pm 0.04)$ & $84.95( \pm 0.04)$ & $169.57( \pm 0.05)$ \\
\hline B1 & $28.07( \pm 0.04)$ & $21.25( \pm 0.03)$ & $81.68( \pm 0.04)$ & $347.65( \pm 0.04)$ \\
\hline B2 & $27.47( \pm 0.04)$ & $21.50( \pm 0.03)$ & $87.10( \pm 0.04)$ & $326.19( \pm 0.04)$ \\
\hline B3 & $28.07( \pm 0.04)$ & $21.56( \pm 0.03)$ & $88.70( \pm 0.04)$ & $256.05( \pm 0.04)$ \\
\hline B4 & $25.97( \pm 0.04)$ & $21.57( \pm 0.03)$ & $88.74( \pm 0.03)$ & $256.20( \pm 0.04)$ \\
\hline B5 & $24.99( \pm 0.03)$ & $21.57( \pm 0.03)$ & $88.91( \pm 0.04)$ & $254.01( \pm 0.03)$ \\
\hline B6 & $26.28( \pm 0.04)$ & $23.31( \pm 0.03)$ & $98.39( \pm 0.03)$ & $213.86( \pm 0.04)$ \\
\hline B7 & $25.48( \pm 0.03)$ & $23.34( \pm 0.03)$ & $100.24( \pm 0.04)$ & $189.86( \pm 0.03)$ \\
\hline B8 & $28.07( \pm 0.04)$ & $23.41( \pm 0.03)$ & $103.96( \pm 0.04)$ & $166.37( \pm 0.04)$ \\
\hline B9 & $27.55( \pm 0.04)$ & $27.26( \pm 0.03)$ & $112.67( \pm 0.04)$ & $146.87( \pm 0.04)$ \\
\hline $\mathrm{B} 10$ & $27.46( \pm 0.04)$ & $26.75( \pm 0.03)$ & $112.39( \pm 0.04)$ & $148.86( \pm 0.04)$ \\
\hline $\mathrm{C} 1$ & $27.38( \pm 0.05)$ & $23.24( \pm 0.04)$ & $103.01( \pm 0.06)$ & $191.09( \pm 0.05)$ \\
\hline $\mathrm{C} 2$ & $25.86( \pm 0.05)$ & $23.34( \pm 0.04)$ & $103.40( \pm 0.06)$ & $189.20( \pm 0.05)$ \\
\hline $\mathrm{C} 3$ & $26.70( \pm 0.05)$ & $23.48( \pm 0.04)$ & $102.38( \pm 0.06)$ & $194.73( \pm 0.04)$ \\
\hline $\mathrm{C} 4$ & $25.86( \pm 0.04)$ & $23.49( \pm 0.04)$ & $103.17( \pm 0.05)$ & $191.57( \pm 0.05)$ \\
\hline $\mathrm{C} 5$ & $27.11( \pm 0.05)$ & $27.53( \pm 0.04)$ & $110.75( \pm 0.06)$ & $143.27( \pm 0.05)$ \\
\hline C6 & $25.81( \pm 0.05)$ & $26.75( \pm 0.04)$ & $124.93( \pm 0.06)$ & $83.09( \pm 0.05)$ \\
\hline $\mathrm{C} 7$ & $27.60( \pm 0.05)$ & $27.53( \pm 0.04)$ & $110.56( \pm 0.06)$ & $144.83( \pm 0.05)$ \\
\hline $\mathrm{C} 8$ & $27.73( \pm 0.05)$ & $27.55( \pm 0.04)$ & $96.92( \pm 0.06)$ & $229.82( \pm 0.05)$ \\
\hline C9 & $29.34( \pm 0.05)$ & $25.59( \pm 0.04)$ & $100.55( \pm 0.06)$ & $161.19( \pm 0.05)$ \\
\hline $\mathrm{C} 10$ & $30.23( \pm 0.06)$ & $21.88( \pm 0.04)$ & $102.38( \pm 0.07)$ & $174.23( \pm 0.06)$ \\
\hline
\end{tabular}

\section{Conclusion}

In this work, a sorptivity coefficient of heterogeneous calcareous stones has been estimated. The importance of this characteristic, especially for porous materials used in cultural heritage, is associated with their durability. Although the experimental tests are very easy to perform, still they require many and large samples. For this reason, an analytical fractal procedure, namely, Intermingled Units model, has been proposed. This modelling procedure is capable of reproducing experimental porous microstructure using fractal base units. After having simulated material microstructures,
IFU model has been used to calculate sorptivity coefficient. The results are in good agreement with experimental ones, which are better than other models reported in the literature. Indeed, $S_{[12]}$ and $S_{[16]}$ are about three-five and three-twelve times higher than experimental data, respectively. The examination of other porous materials could offer the possibility to generalise fractal procedure and to extend the application fields. The possibility to predict water sorptivity and movement into microstructure may represent an important step forward in the field of conservation of cultural heritage for estimating service life of porous building materials. 


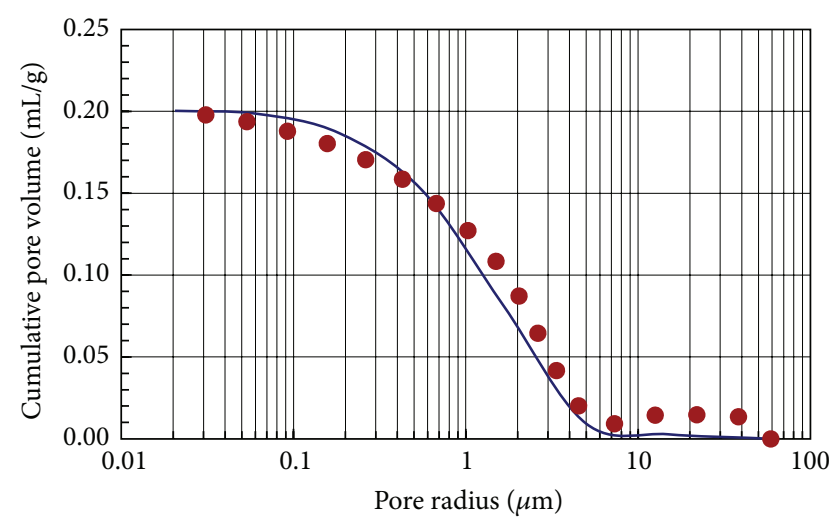

(a)

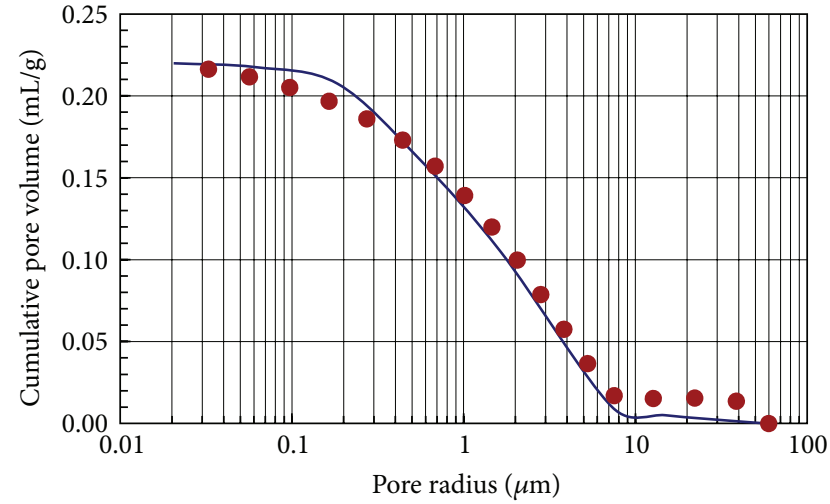

(b)

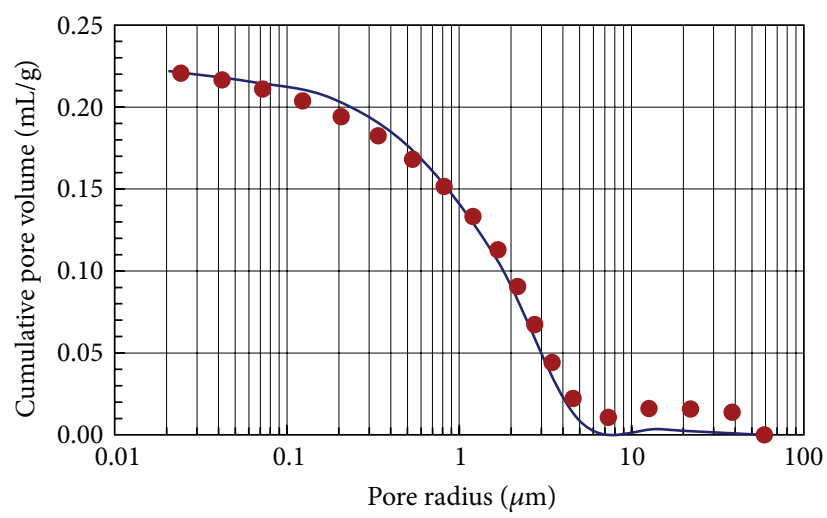

(c)

FIgURE 4: Comparison between experimental (continuous line) and IFU (dot line) pore cumulative curves A3 (a), B5 (b), and C2 (c).

\section{Competing Interests}

The authors declare that they have no competing interests.

\section{References}

[1] E. Franzoni, "Rising damp removal from historical masonries: a still open challenge," Construction and Building Materials, vol. 54, pp. 123-136, 2014.

[2] C. Di Benedetto, P. Cappelletti, M. Favaro et al., "Porosity as key factor in the durability of two historical building stones: neapolitan Yellow Tuff and Vicenza Stone," Engineering Geology, vol. 193, pp. 310-319, 2015.

[3] C. Atzeni, G. Pia, U. Sanna, and N. Spanu, "A fuzzy model for classifying mechanical properties of vesicular basalt used in prehistoric buildings," Materials Characterization, vol. 59, no. 5, pp. 606-612, 2008.

[4] E. Sassoni and E. Franzoni, "Influence of porosity on artificial deterioration of marble and limestone by heating," Applied Physics A: Materials Science and Processing, vol. 115, no. 3, pp. 809-816, 2014.

[5] F. Sandrolini and E. Franzoni, "An operative protocol for reliable measurements of moisture in porous materials of ancient buildings," Building and Environment, vol. 41, no. 10, pp. 13721380, 2006.

[6] G. W. Scherer, "Stress from crystallization of salt," Cement and Concrete Research, vol. 34, no. 9, pp. 1613-1624, 2004.
[7] J. Martínez-Martínez, D. Benavente, M. Gomez-Heras, L. Marco-Castaño, and M. Á. García-Del-Cura, "Non-linear decay of building stones during freeze-thaw weathering processes," Construction and Building Materials, vol. 38, pp. 443-454, 2013.

[8] E. Franzoni and E. Sassoni, "Correlation between microstructural characteristics and weight loss of natural stones exposed to simulated acid rain," Science of the Total Environment, vol. 412-413, pp. 278-285, 2011.

[9] T. Wangler and G. W. Scherer, "Clay swelling mechanism in clay-bearing sandstones," Environmental Geology, vol. 56, no. 34, pp. 529-534, 2008.

[10] C. Gentilini, E. Franzoni, S. Bandini, and L. Nobile, "Effect of salt crystallisation on the shear behaviour of masonry walls: an experimental study," Construction and Building Materials, vol. 37, pp. 181-189, 2012.

[11] E. Sassoni, E. Franzoni, B. Pigino, G. W. Scherer, and S. Naidu, "Consolidation of calcareous and siliceous sandstones by hydroxyapatite: comparison with a TEOS-based consolidant," Journal of Cultural Heritage, vol. 14, no. 3, pp. e103-e108, 2013.

[12] G. W. Scherer and G. S. Wheeler, "Silicate consolidants for stone," Key Engineering Materials, vol. 391, pp. 1-25, 2009.

[13] C. Cardell, D. Benavente, and J. Rodríguez-Gordillo, "Weathering of limestone building material by mixed sulfate solutions. Characterization of stone microstructure, reaction products and decay forms," Materials Characterization, vol. 59, no. 10, pp. 1371-1385, 2008. 
[14] E. Franzoni, E. Sassoni, G. W. Scherer, and S. Naidu, "Artificial weathering of stone by heating," Journal of Cultural Heritage, vol. 14, no. 3, pp. e85-e93, 2013.

[15] Istituto Centrale del Restauro, "Conservazione dei materiali lapidei: manutenzione ordinaria e straordinaria," Recommendation NORMAL 20/85, Istituto Centrale del Restauro, 1985.

[16] M. Raimondo, M. Dondi, D. Gardini, G. Guarini, and F. Mazzanti, "Predicting the initial rate of water absorption in clay bricks," Construction and Building Materials, vol. 23, no. 7, pp. 2623-2630, 2009.

[17] G. Pia and U. Sanna, "An intermingled fractal units model to evaluate pore size distribution influence on thermal conductivity values in porous materials," Applied Thermal Engineering, vol. 65, no. 1-2, pp. 330-336, 2014.

[18] B. B. Mandelbrot, The Fractal Geometry of Nature, W. H. Freeman and Co, New York, NY, USA, 2004.

[19] K. Falconer, Fractal Geometry: Mathematical Foundation and Applications, John Wiley \& Sons, New York, NY, USA, 2nd edition, 2003.

[20] M. Arandigoyen, J. L. P. Bernal, M. A. B. López, and J. I. Alvarez, "Lime-pastes with different kneading water: pore structure and capillary porosity," Applied Surface Science, vol. 252, no. 5, pp. 1449-1459, 2005.

[21] D. N. Winslow, "The fractal nature of the surface of cement paste," Cement and Concrete Research, vol. 15, no. 5, pp. 817-824, 1985.

[22] K. Li and R. N. Horne, "Fractal modeling of capillary pressure curves for the Geysers rocks," Geothermics, vol. 35, no. 2, pp. 198-207, 2006.

[23] J. Cai, X. Hu, D. C. Standnes, and L. You, "An analytical model for spontaneous imbibition in fractal porous media including gravity," Colloids and Surfaces A: Physicochemical and Engineering Aspects, vol. 414, pp. 228-233, 2012.

[24] J. Cai, E. Perfect, C.-L. Cheng, and X. Hu, "Generalized modeling of spontaneous imbibition based on hagen-poiseuille flow in tortuous capillaries with variably shaped apertures," Langmuir, vol. 30, no. 18, pp. 5142-5151, 2014.

[25] J. Cai, B. Yu, M. Zou, and L. Luo, "Fractal characterization of spontaneous co-current imbibition in porous media," Energy and Fuels, vol. 24, no. 3, pp. 1860-1867, 2010.

[26] J. Cai and B. Yu, "A discussion of the effect of tortuosity on the capillary imbibition in porous media," Transport in Porous Media, vol. 89, no. 2, pp. 251-263, 2011.

[27] J. Cai, L. Luo, R. Ye, X. Zeng, and X. Hu, "Recent advances on fractal modeling of permeability for fibrous porous media," Fractals, vol. 23, no. 1, Article ID 1540006, 2015.

[28] G. Pia and U. Sanna, "A geometrical fractal model for the porosity and thermal conductivity of insulating concrete," Construction and Building Materials, vol. 44, pp. 551-556, 2013.

[29] G. Pia, L. Casnedi, and U. Sanna, "Porous ceramic materials by pore-forming agent method: an intermingled fractal units analysis and procedure to predict thermal conductivity," Ceramics International, vol. 41, no. 5, pp. 6350-6357, 2015.

[30] G. Pia, L. Casnedi, M. Ionta, and U. Sanna, "On the elastic deformation properties of porous ceramic materials obtained by pore-forming agent method," Ceramics International, vol. 41, no. 9, pp. 11097-11105, 2015.

[31] C. Atzeni, G. Pia, U. Sanna, and N. Spanu, "A fractal model of the porous microstructure of earth-based materials," Construction and Building Materials, vol. 22, no. 8, pp. 1607-1613, 2008.
[32] C. Atzeni, G. Pia, U. Sanna, and N. Spanu, "Surface wear resistance of chemically or thermally stabilized earth-based materials," Materials and Structures, vol. 41, no. 4, pp. 751-758, 2008.

[33] G. Pia, E. Sassoni, E. Franzoni, and U. Sanna, "Predicting capillary absorption of porous stones by a procedure based on an intermingled fractal units model," International Journal of Engineering Science, vol. 82, pp. 196-204, 2014.

[34] G. Pia and U. Sanna, "An intermingled fractal units model and method to predict permeability in porous rock," International Journal of Engineering Science, vol. 75, pp. 31-39, 2014.

[35] UNI EN 15801: Conservation of Cultural Property-Test Methods-Determination of Water Absorption by Capillarity, 2013.

[36] F. A. L. Dullien, Porous Media: Fluid Transport and Pore Structure, Academic Press, San Diego, Calif, USA, 1992.

[37] G. Borsoi, B. Lubelli, R. van Hees, R. Veiga, and A. S. Silva, "Understanding the transport of nanolime consolidants within Maastricht limestone," Journal of Cultural Heritage, vol. 18, pp. 242-249, 2016. 

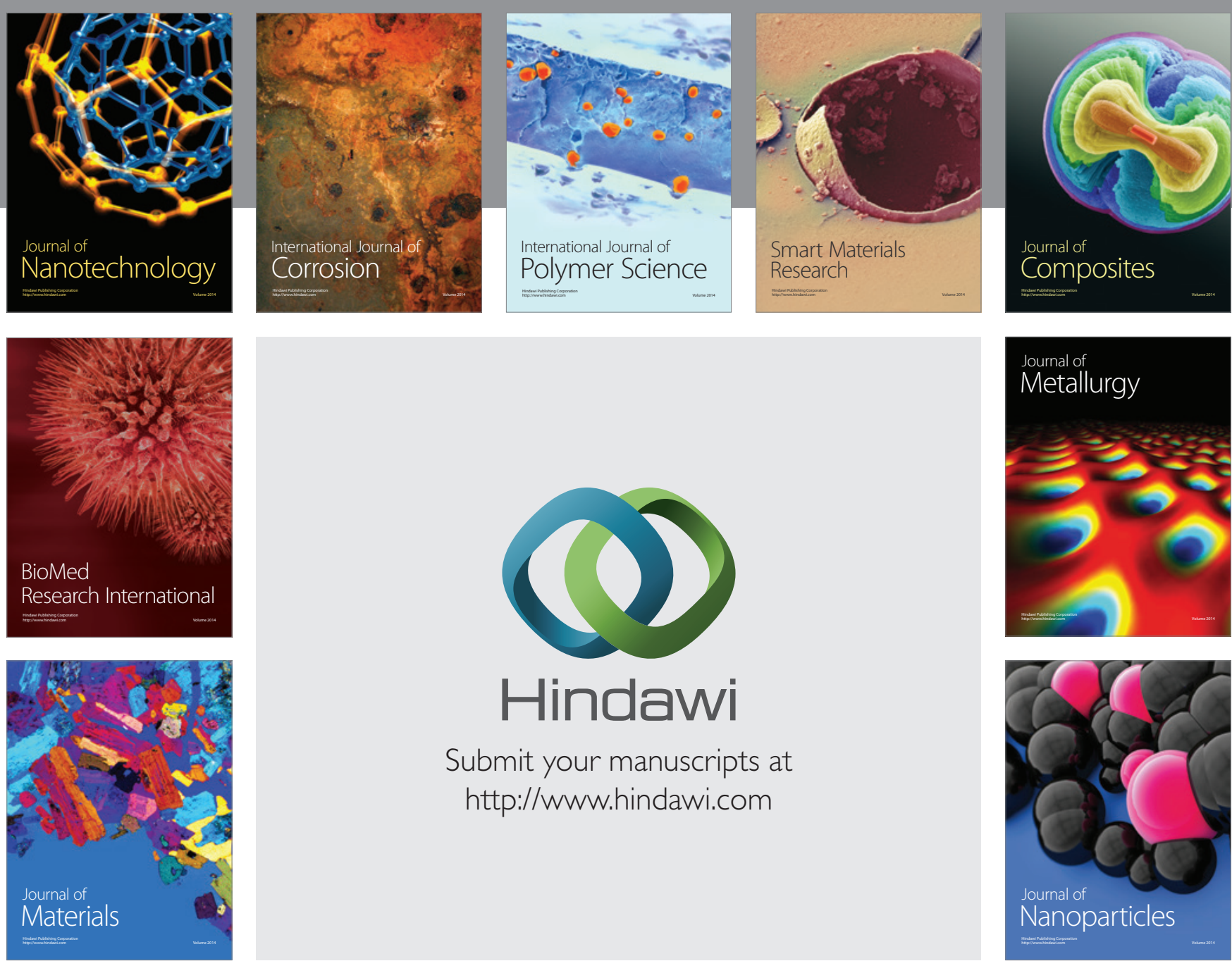

\section{Hindawi}

Submit your manuscripts at

http://www.hindawi.com

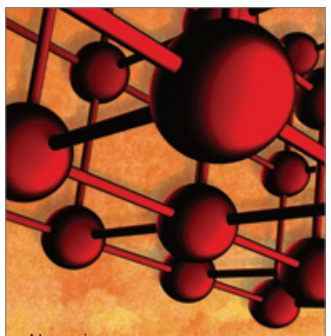

Materials Science and Engineering
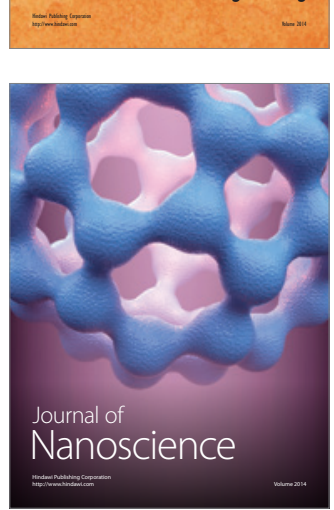
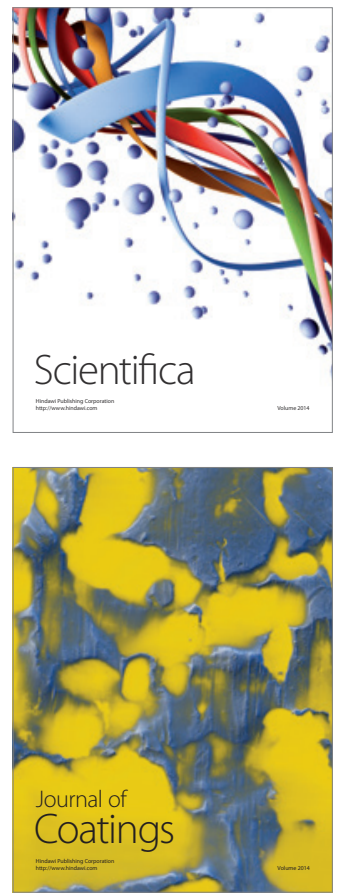
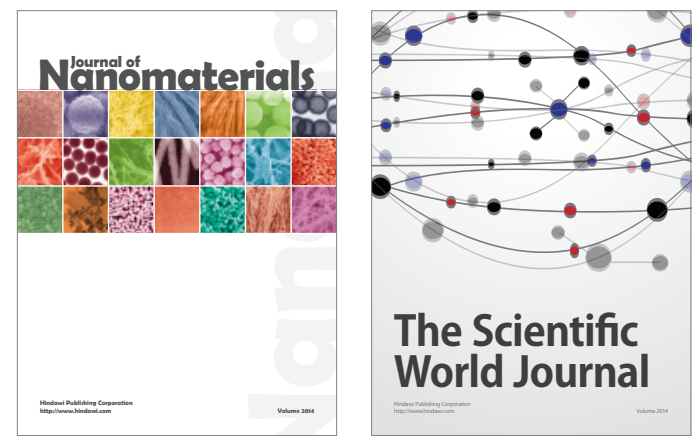

The Scientific World Journal
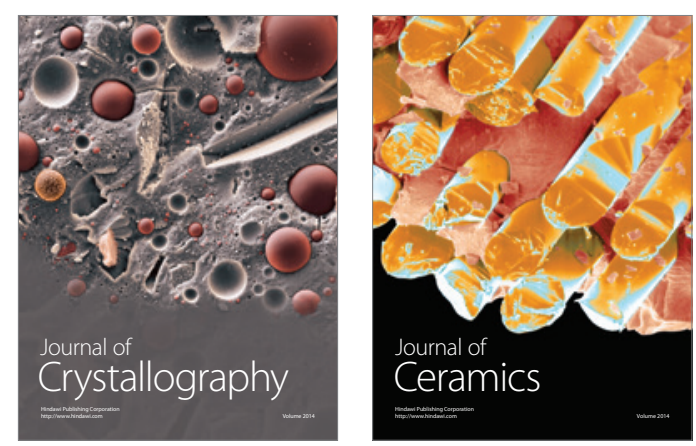
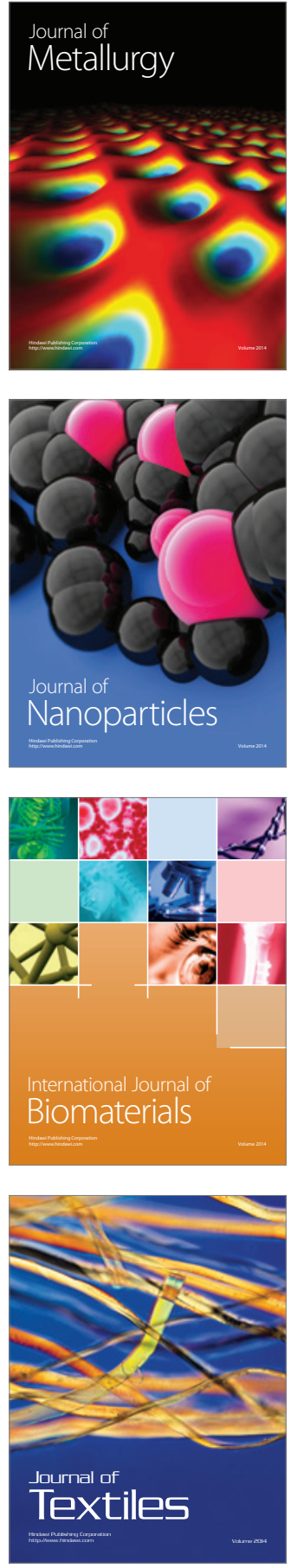